\title{
Wallenstein's Power Problem and Its Consequences
}

\section{Manfred J. Holler*, Barbara Klose-Ullmann ${ }^{\dagger}$}

\author{
Received 30 July 2008; Accepted 5 December 2008
}

\begin{abstract}
This paper wants to be both: an introduction to game-theoretical thinking as well as a game-theoretical discussion of Schiller's Wallenstein. Note that the intention of this article is to convince theatergoers and people who work in the theatrical arts that it is worthwhile to study some game theory. Others will hopefully profit from the unusual Wallenstein interpretation. It is not this article's purpose to teach game theorists, but rather to inspire applications. The drama is depicted as a game and consequently submitted to a formal analysis that is based on the economic concept of rationality. Weber's definition of power is operationalized and applied to Wallenstein's decision situation.
\end{abstract}

Keywords Power, bargaining, mixed-strategy Nash equilibrium, theater, Wallenstein JEL classification C72, D82, K00

\section{Introduction: the curtain rises}

"Partisan hatreds and affections shroud/His character, as history portrays it."(Prologue) It should be noted here that we are not dealing with the actual Wallenstein, Duke of Friedland (1583-1634). Never has a document been found which has proved that the historic Wallenstein ever intended to betray his Emperor. In spite of this, even Wallenstein's most ardent advocates are known to have suspected his rather lukewarm support of "the Emperor's cause" - feeling that his ambitions were going beyond simply being the Emperor's sword which the latter could draw or discard, according to his whim. In this paper we will deal with Schiller's Wallenstein whose actions differ from those of the historic Wallenstein according to the poet's intention. His character corresponds to how he was perceived in the late 18th century. It is not surprising that even today this perception prevails as it has to a large extent been shaped along Schiller's Wallenstein.

Also, we have to distinguish between Schiller as poet and as historian. We are referring to the poet, to the way he conceived his leading character, to his dramatic poem, the trilogy "Wallenstein's Camp", "The Piccolomini", and "Wallenstein's Death". In the play, certain problems are overemphasized and made subject to analytical scrutiny which we would hardly take note of, when considering the relevant historical developments. This is the kind of literary achievement we demand from the author, an approach we take advantage of as a basis for our own interpretation in this paper. As

\footnotetext{
* Universität Hamburg, Institute of SocioEconomics, IAW, Von-Melle-Park 5, D-20146 Hamburg, Germany. Phone +49 4042838 4458, E-mail: holler@econ.uni-hamburg.de.

$\dagger$ Munich Institute of Integrated Studies (GIS), Gnesener Str. 1, D-81929 Munich, Germany. Phone +49 89 935714, E-mail: bku-info@klose-ullmann.de.
} 
Norbert Oellers (2005, p.145f.) observed, this "trilogy has been examined with the most different methods and from seemingly all angles (strictly philological, historical, philosophical, in terms of literature comparison, of liberal arts and social history, work immanent, critical of the style and system, also applying discourse theory and deconstructivism)", but "analysis and interpretation" [of the work] seems "to lend itself to infinite variations." 1 This paper applies a radically new perspective. On the one hand, its interpretation is based upon game theory: the "mathematics of conflict and coordination." On the other hand, it looks at a rather limited string of the action: Wallenstein's negotiations with the Swedish Colonel Wrangel. Choosing this perspective, we hope to learn more about the nature of bargaining and gain further insights into concepts such as trust and power. Besides this we also hope and expect that the game-theoretical analysis contributes to the interpretation of Schiller's play.

Game theory, with its set of tools sharpened by individual rationality, seems to be a suitable instrument to render new understanding within this context possible. This does not mean to imply that the historic Wallenstein was acting rationally in a gametheoretical sense. Neither do we assume that Schiller imputed to his main character rational action. We just want to see which results we obtain if we apply the theory which, from today's economic, philosophical, and psychological point of view, accounts for the core of scientific decision theory. Game theory is used to clarify such different phenomena as the crisis which was triggered in 1962 by the stationing of Sovjet rockets equipped with atomic warheads in Cuba or the auctioning of UMTS licenses for mobile telephones which took place in Germany in 2000.

This paper wants to be both: an introduction to game-theoretical thinking as well as a game-theoretical discussion of Schiller's Wallenstein. Note that the intention of this article is to convince theatergoers and people who work in the theatrical arts that it is worthwhile to study some game theory. Others will hopefully profit from the unusual Wallenstein interpretation. It is not this article's purpose to teach game theorists, but rather to inspire applications and to inspire novel interpretations and explanations. If we abstract from the murderous end, there is hardly any action, but much talking, guessing, thinking and even dreaming, and therefore little to observe for the players. As imperfect information is prominent, the analysis of the strategic form and the use of simple game matrices may help us to reveal some interesting aspects of the play.

What does it mean to give an explanation? If we follow Michael Baxandall's approach of explanation, as proposed in his "Patterns of Intention" (1985), we first postulate a hypothetical cause (i.e., a causal proposition), then choose the specific circumstances and relate the derived solutions to what is to be explained (trust, affection, responsibility, treason, success, power, etc.). In our case, the hypothetical cause is the rationality of decisions and actions in game-theoretical sense. In the next chapter, we will deal with it more at length. The poet sets the specific circumstances with his play, including his design of characters, social relations, location and time. They describe a "market place" 2 on which the hypothetical causes become effective and induce results.

\footnotetext{
1 Norbert Oellers (2005) quotes from Rainer Godel's (1999) Schillers Wallenstein-Trilogie.

2 Baxandall (1985, p. 47ff.) uses the word "le troc" which can be translated by "market", but implies a very general application of this concept.
} 
We analyse the latter with regard to trust, affection, responsibility, treason, success, power, etc. in order to help distil a solution to their explanation.

However, concepts such as trust are only "images" of real-world experiences. As a first step, reality must be described (or defined). Only then can they be put in the verbalized context with the causes and the specific circumstances, which are also being described. Analysing the printed version of a play means that the material is already available in verbalized form. However, its interpretation also depends on the reader's perspective of life, his knowledge and experience and the questions he asks from the play. There is still a reading problem and, of course, a selection problem. Both are highly relevant for what follows. The Wallenstein trilogy gives a host of decision situations that can be examined for their specific circumstances and solutions. Wallenstein's negotiations with Colonel Wrangel are just one, but feasibly the most prominent incidence. We shall see whether its analysis helps to get a better understanding of Wallenstein.

\section{Wallenstein's negotiates with the Swedes}

Wallenstein's Death, Act 1, Scene 5: The Swedish Colonel Wrangel comes to Wallenstein on a secret mission. The long-lasting bargaining between Wallenstein and the Swedes concerning joint action is finally to be concluded. By allying with the Swedes, Wallenstein hopes to gain the Bohemian crown and to reinstall Protestantism in Bohemia, as well as to finish the war between the Catholic League and the protestant north, including Sweden. The Swedes, on the other hand, want to expand the protestant territory, under their rule or dominance, to the largest extent possible.

At first, they talk about the siege of Stralsund in 1628. Wrangel defended the city for the Swedes. Wallenstein's then besieging troops were forced to withdraw without success.

Wallenstein: You wrested from my head the admiral's hat.

Wrangel: Today I come to set crown upon it.

Wallenstein: Your papers. Have you full authority?

Wrangel: So many doubts remain to be resolved.

Wallenstein (after reading): A letter to the point. It is a shrewd/And wily master, Wrangel, that you serve./ Your chancellor declares that it is but/ The late king's own intent he carries out/ In helping me to the Bohemian crown.

Wrangel hints at the Swedes' doubting that he, Wallenstein, the Duke of Friedland, would indeed become unfaithful to the Emperor and ally with the Swedes. To them it is even less imaginable that he would succeed in persuading a force of 18,000 men "... To break their oath of loyalty." Wallenstein points out that the Emperor's army, which he recruited, consists of soldiers from many different countries. Actually, some of them came from Bohemia. Indeed, their fathers and grandfathers had already vehemently been opposed to the Hapsburgs who had forced them to become Catholic. Regarding the nobility and the officers under his command, he goes so far as to say "In any circumstances, they are mine." He shows Wrangel a declaration signed by all generals and commanders (except Max Piccolomini) which confirms their loyalty. 
This convinces Colonel Wrangel. "I will drop my mask - indeed!/ I have authority to act in this."

Nevertheless, for safety reasons, as "Everything might yet be trickery," Wrangel demands from Wallenstein to disarm the Spanish regiments loyal to the Emperor, and to hand the border fortress Eger as well as Prague over to the Swedes. Wallenstein strongly rejects the occupation of Prague: "Give up my capital to you! Why, rather/ Rejoin my Emperor!" Wrangel: "If there is time." Wallenstein: "That I am free to do, today and always." However, Wrangel points out to him that he lost such freedom to act when his secret emissary Sesina was captured by soldiers loyal to the Emperor. Wallenstein, taken aback, offers no reply. Yet, Wrangel yields: “...We believe that you are in good faith;... No quarrels over Prague, Our chancellor/Will only take the Old Town..."

At the end of the meeting, Wallenstein asks "I must trust you, but you will not trust me? I will consider what you have proposed."

After Wrangel leaves, Wallenstein's sister-in-law, Countess Terzky, enters ("Wallenstein's Death", Act 1, Scene 7). Wallenstein feeling oppressed by Wrangel's proposal, complains to her that he has no choice any more. As a response, she points out a more peaceful way that still lies open to him, namely to retreat to his domains: “... The Duke is just another one/ Of those new men, who rose up overnight upon/ The tide of war, a creature of court favour,/ That makes a prince as soon as make a baron."

Wallenstein is appalled by this prospect and as a consequence, Countess Terzky urges him to act. In a fulminating speech, she claims: "It is not Wallenstein who is betraying the Emperor but it is the Emperor who did terrible injustice to him when he let him fall victim to the Imperial Diet and, a while later, because of harsh necessity, reinstalled him as commander in chief." He, Wallenstein, as the Countess continues, has always remained true to himself. "...they are in the wrong, who were afraid/ Of you and yet put power in your hands./ A man of character is always right/ If but consistent with himself, there is/ No wrong for him except in contradiction."

Wallenstein's military campaigns, drenching the lands of friends and foes with blood, were always approved by the Emperor. The Emperor thus also committed a great wrong. "What profited the Emperor, that pleased him;/ And silently he set upon those crimes/ The seal of his approval. What was right/ Then when you did it for him, is it now/ Become at once so wicked, when a g a i n s t/ Him it is turned?" Countess Terzky points out that between Wallenstein and Emperor Ferdinand "... There never can be talk of right and duty,/ Only of power, and opportunity!" Wallenstein is convinced, and he agrees to the Swedish proposal.

But was this a good choice for him? We could answer this question if we knew what Wallenstein really wanted. However, this is not at all clear to the reader. This ambiguity forms an integral part of the play.

\section{From the stage to the game matrix}

A game consists of players and rules. The latter are describing the possible actions (strategies) and outcomes in the course of the game, and are specifying the players' 
information. A game assumes that the players evaluate the outcomes, e.g., they prefer winning to losing and being rich to being poor.

At first glance it should not be difficult to perceive a theater play as a game in the sense of game theory. Usually, the author gives us a list of all the characters of his play before he will confront us with the first scene. Prima facie, it would make sense to consider these characters as players and the chronology of their appearance on stage as a sign of their significance. However, in "Wallenstein's Camp", there is no Wallenstein; he is not listed and does not appear in the first part of Schiller's trilogy. Yet, he is the overpowering player who ubiquitously dominates every scene. The people in the camp are permanently talking about one topic: the scope of his power. As the SergeantMajor states in Scene 11, "He has the power absolutel To make war or peace, as it may suit;/ He can confiscate money or property,/ Can execute, or show clemency,/ He can promote, or grant a commission,/ All the matters of honour are at his disposition:/ The Emperor himself gave him this as his right." Some lines later he adds, "Is he not a prince, as good as the next?/ Hasn't he his own coinage like Ferdinand?/ His own people and his own land?/ Men call him Your Highness, and bow to him deep./ His own soldiers he must be able to keep." This does not only emphasize Wallenstein's princely standing, it also introduces a second player who never appears on stage: Emperor Ferdinand. He is instrumental in "Wallenstein's Death", the last part of the trilogy.

To include Wallenstein and the Emperor is the first step towards answering one of the central questions which game theory poses to a decision situation modelled as a game: Who are the players? The answer to this question, which should also be posed by the players in order to optimally solve a decision situation, may decide the outcome of the game. It seems that Wallenstein himself sometimes forgot that the Emperor was also a player.

Often, theater plays describe clearer what the players can and cannot do, which alternatives they have or haven't, than a mere description of reality would allow for. However, this is only true for the string of action described. We cannot even imagine how Schiller's Wallenstein would have acted as Bohemian King, whereas we might be able to dare a prognosis on the basis of the data of the historic Wallenstein, well-known to Schiller. The historic Wallenstein was a gifted organiser and planner; his dukedom of Friedland was much better administered than other parts of the German Reich. But as the myth of Wallenstein covers the historic image, it makes sense to resort to Schiller's Wallenstein. He is not confronted with the question of how to administer the Bohemian kingdom but rather if he could, and with what means he should pursue to become king of Bohemia. The rules of the theater play provide him with only two alternatives: either to accept the Swedish proposal or just pretend to accept it and then defeat the Swedes.

Which of the two strategies is more successful depends on the action of the Swedes, i.e., which strategy they choose, because, in general, the choices of all players determine the outcome of the game in a game situation. In other words, if a player has no influence on the outcome or is incapable of exerting influence, he is not a player. This is true for most of the cuirassiers, arquebusiers and ulans thronging Wallenstein's camp. Yet the poet is convinced that they are contributing to the outcome. Otherwise he would not put them on stage, not to mention letting some of them speak. Also from 
the point of view of the audience, each one of them may contribute to the interpretation of the play and help define the actions of the main characters. For good reasons, the theater is distinguishing between major and minor roles. As to the first part of the trilogy, "Wallenstein's Camp", this distinction is, however, not obvious. We might argue that the "major roles remain uncast."

To understand game theory, it is of utmost importance to realize that events result from the interaction of several players. If the outcomes of a decision situation are determined by one player only, there is no game implied, and therefore the application of game theory could not generate useful answers under such circumstances.

In game theory, plans of actions are summarized as strategies. A strategy assumes that each player knows in advance how he (or she) will act in a well-defined situation; it assumes that each player enters the game with a "complete theory." 3 Everything a player can conclude about the actions of the other players and the possible outcome of random moves is taken into consideration when formalizing his (or her) strategies. This assumption makes it possible to capture the sequence of decisions (moves) and random moves (draws) in the form of strategies, and to represent the game in matrix form, despite of the dynamics of the game. In this case, however, information that is gained during the course of the game cannot be incorporated. If Wallenstein opts for cooperation with the Swedes, his strategy will contain a response to the case that the Swedes do not only occupy the Old Town of Prague, but all of it. As a strategy should also include random moves, like draws of a lottery, Wallenstein's strategies should also contain actions relating to the Vltava (Moldau river) overflowing its banks and flooding the center of "his capital" to such an extent that a large share of the population and also of the occupants are in danger of drowning. What Wallenstein is planning today as part of his strategy, can be rather useless, given the arrival of this event. However, it is crucial what Wallenstein decides today: Will he cooperate with the Swedes or not?

There is still an important ingredient missing in the description of a game: the evaluation of the outcomes by the players. In game theory, this evaluation is expressed by real numbers that represent the payoffs to a particular player. In an older version of decision theory, these numbers are the utilities (measured in "utils") to the player. Today's utility theory says that a value of 4 that player $j$ assigns to outcome $A$, implies that $j$ prefers $A$ to $B$ if he assigns a 2 or -4 to the latter outcome. Thus the numbers represent merely an ordinal scale. However, when uncertainty enters the scene, either because of random moves like the flooding Moldau or because players choose mixed strategies, then we need cardinal values that can be multiplied with probabilities. Cardinality implies that the distance between two values, 4 and 2 or, alternatively, 4 and -4 , has some meaning. If player 1 assigns a value of 4 to outcome $A$ and a value of 2 to outcome 2 , then the value of a lottery is 3 if the two outcomes are expected to occur with probability $1 / 2$. By the same probabilities the expected value is 0 , if the values of $A$ and $B$ are 4 and -4 , respectively. If a third alternative $C$ exists and the player $i$ assigns a value of 1 , then $i$ will prefer the lottery with an expected value of 3 to alternative $C$. However, $i$ prefers the alternative $C$ to the lottery with an expected value

3 This notion of strategy was already proposed in John von Neumann's "Zur Theorie der Gesellschaftsspiele" (1928), the most influential pioneer paper of game theory. 
of 0. This is what expected utility theory tells us. The expected values are expected utility: In game theory they are called payoffs or von Neumann Morgenstern utilities. ${ }^{4}$

Thus, if we follow modern theory, payoffs represent preferences or choices. Older theories will interpret payoffs as utilities. Following this definition, ${ }^{5}$ payoffs are not money. However, this does not exclude that players express their payoffs (utilities or preferences alike) in monetary terms.

For Wallenstein, money plays a minor role; it functions only as a means to buy the loyalty of his soldiers. However, he seems to consider the recruitment of a large army of sixty thousand men a better way to guarantee loyalty, since it entails providing a home for every single soldier along with their presumed privilege to plunder each and every citizen or peasant they happen to come across (cf. "Wallenstein's Camp", Scene 11). Therefore there is much unrest in the camp when the rumor springs up that eight thousand "cuirassiers, sharpshooters and troopers" are to be sent to the Netherlands to support the "Spaniard", the Infant. "And take the field with the Spaniard vile,/ The skinflint whom we all hate and deride?/ No, we'll not do it! We'll desert, I swear." ("Wallenstein's Camp", Scene 11.)

\section{Game-theory models}

Now we can formulate simple game-theoretical models which reflect aspects of the decisions that determined the fate of Schiller's Wallenstein. Thereby, we do not take into account the stars that were said to have played a major role to Wallenstein's fate as well. We concentrate on the negotiations between Wallenstein and Wrangel and try to interpret them by using game theory.

The following Matrix 1 describes the decision situation with Wallenstein, on the one side, and the Swedes, represented by Wrangel, on the other. They are the players. This simple model corresponds to the situation as outlined in section 2. Each player has two alternatives from which to choose, the pure strategies "cooperate" and "not cooperate." Everything in the course of time that is connected with these alternatives such as the occupation of Eger and Prague, the conflict with rebellious troops, fighting against imperial troops, being ambushed by desperate peasants, is incorporated in these strategies.

The players can choose pure and mixed strategies. If Wallenstein plays a mixed strategy he leaves it to chance as to whether "cooperate" or "not cooperate" will be selected and executed. This implies at least one advantage: Wrangel will face great difficulties to forecast Wallenstein's behavior. If Wallenstein does not know which pure strategy he will execute in the end, Wrangel cannot know Wallenstein's final choice. However, Wallenstein can manipulate chance. If he decides by tossing a coin, this is equivalent to a random draw of probability $1 / 2$ for each of his pure strategies.

\footnotetext{
${ }^{4}$ In their pioneering book, Theory of Games and Economic Behavior, John von Neumann and Oskar Morgenstern (1944) presented an axiomatization of this type of utility function.

5 However, sometimes it is convenient to interpret payoffs as money or as corresponding real outcomes. For instance, this is the case if we discuss effects of risk aversion that implies a comparison of e.g. money and utility values under risk. There are authors who prefer the money definition of payoffs to its utility construction.
} 
If Wallenstein concludes that $1 / 2$ is too high a probability for "cooperate", then he can find a random mechanism that produces, for instance, a probability distribution $(1 / 3$, $2 / 3$ ) on his two pure strategies. To achieve this result by tossing a dice, he can assign numbers 1 and 2 to the strategy "cooperate" and numbers 3, 4, 5 and 6 to strategy "not cooperate." Such a random draw makes sense only if the other player is convinced that the result of the random choice is binding, i.e., if Wallenstein decides for "cooperate" without any further qualifications, given that the dice shows a 1 .

Matrix 1. Wallenstein's indifference

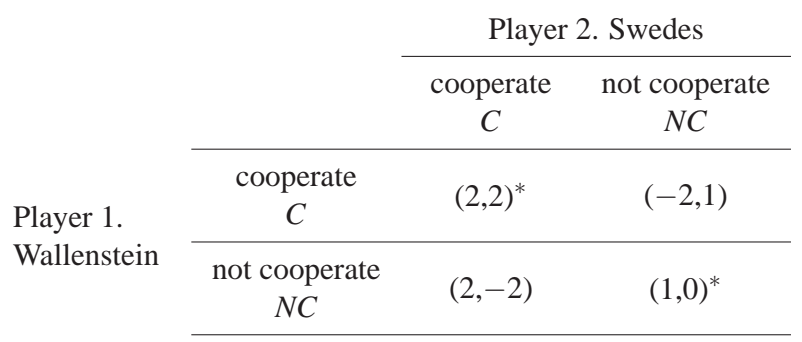

The players choose their strategies. The matrix expresses that the result (outcome) depends on the strategy choices of both players. Given strong simplifications, Schiller's text allows us to relate the pairs of pure strategies to the outcomes as follows.

$(\mathrm{C}, \mathrm{C})$ : Wallenstein receives the royal crown of Bohemia. Bohemia becomes a protestant country. The Swedes are allowed to occupy Eger and the Old Town of Prague.

$(\mathrm{NC}, \mathrm{C})$ : Wallenstein's troops join the imperial troops and defeat the Swedish who were prepared to cooperate and behaved accordingly. The results are peace in "catholic" Bohemia and heavy casualties incurred by the Swedes.

(C, NC): Wallenstein is abandoned by the Swedish troops. His army falls apart and he is prosecuted for high treason. The Swedes cover Bohemia with pilferage and war.

(NC, NC): Wallenstein remains Imperial Commander-in-Chief; the war continues.

A matrix that relates the chosen strategies to outcomes is called game form. Matrix 1, however, goes one step further: It does not show outcomes, but how the players evaluate the various outcomes that result from the strategy choices. The pair $(2,2)$ evaluates the outcome that results from the strategy pair $(C, C)$. The evaluation implies that both players prefer the corresponding outcome to the outcome that follows from choosing $(N C, N C)$. The payoff pair $(1,0)$ represents the evaluation of the outcome that is determined by $(N C, N C)$.

The matrix demonstrates that a player cannot choose outcomes or payoff pairs but strategies only. A specific payoff pair will be selected by the strategy choices of both players. 


\section{More than one equilibrium}

The game in Matrix 1 has two Nash equilibria in pure strategies $(C, C)$ and $(N C, N C)$. The corresponding payoff pairs are characterized by the symbol ${ }^{*}$. If player 1 chooses strategy $C$, player 2 cannot do better than to choose his strategy C. In a two-person game, a Nash equilibrium is a pair of strategies that are mutual best-replies (to each other): A player cannot achieve a higher payoff by choosing a different strategy, given the strategy of the other player. This definition can be extended to more than two persons, as we will see. The definition also fits to strategy pair $(N C, N C)$ although both players could do better if both choose strategy $C$ instead of $N C$. A Nash equilibrium is stable only with respect to the deviation of one player, given the strategies of the other players. It follows that not all Nash equilibria are efficient. Efficiency here means that one player cannot get a higher payoff, given the payoff of the other player(s). ${ }^{6}$

In addition to the two equilibria in pure strategies, the game in Matrix 1 has an equilibrium in mixed strategies: if Wallenstein chooses $C$ with probability $p^{*}=2 / 3$, and $N C$ with $1-p^{*}=1 / 3$, the Swedes are indifferent between $C$ and $N C$. Then, of course, they are also indifferent between all lotteries that assign some probability $p$ to $C$ and $1-p$ to $N C$. Therefore, even $C$ is a best reply for them. However, if the Swedes choose $C$ then Wallenstein is indifferent between $C$ and $N C$ and linear combinations of these strategies. If Wallenstein chooses $C$ with probability $p^{*}=2 / 3$ and the Swedes choose $C$ with probability $q^{*}=1$, then none of the two players can achieve a higher payoff, given the strategy of the other player. Therefore, $p^{*}=2 / 3$ and $q^{*}=1$ are mutually best replies and therefore satisfy the conditions of a Nash equilibrium. Formally the Nash equilibrium can thus be written as $\left(p^{*}, q^{*}\right)=(2 / 3,1)$.

Which strategies will Wallenstein and the Swedes choose? If we are not happy with the answers that are derived from the Nash equilibria - why should we be? - we can try to get further insights into the structure of the bargaining problem through an application of the maximin solution. First of all we notice that the game in Matrix 1 has no maximin solution in mixed strategies since the interval $[0,1]$ does not contain a probability $p$, such that the expected utility of the Swedes from applying strategy $C$ is identical to the utility value from choosing $N C$ : If the Swedes choose $C$, then Wallenstein's expected utility will be 2 . However, if they choose $N C$, then Wallenstein's expected value, $p(-2)+(1-p) 1$, will be smaller than 2 .

The corresponding result holds true for the Swedes. They can always win a higher payoff if Wallenstein chooses $C$ than if he chooses $N C$. The maximin solution will be in pure strategies. Wallenstein's maximum of the minima payoffs (of each pure strategy) is 1 . It corresponds to strategy $N C$. The maximin value of the Swedes is 0 and the corresponding strategy is $N C$. Thus the maximin solution selects the strategy pair $(N C, N C)$ and the corresponding payoff pair $(1,0)$.

As we concluded above, $(N C, N C)$ is a Nash equilibrium in pure strategy. Perhaps this gives further justification to submit this result for further analysis. Obviously, not every strategy pair that constitutes a maximin solution satisfies the conditions of

\footnotetext{
6 This criterion of efficiency is identical with Pareto optimality, given that the set of individuals under
} (welfare) consideration is identical with the set of players. 
Nash equilibrium. However, does the concurrence of Nash equilibrium and maximin solution propose $(N C, N C)$ as a point of departure of a plausible description of likely outcomes?

Wallenstein: "The Empire shall revere me as its saviour;/ Myself conducting as befits a Prince/ Of Empire, I shall take any place among them./ I shall allow no foreign power to gain/ A foothold in the Empire, least of all/ These Goths, the hungry, frozen savages/ Who cast their greedy eyes so jealously/ Upon the fruitful lands of Germany./ They shall be there to help me in my plans,/ But there shall be no pickings for them, no!" ("The Piccolomini", Act 2, Scene 5.)

Wallenstein's remarks to Count Terzky, his brother-in-law, seem to suggest that $N C$, "not cooperate" is his preferred (i.e. "dominant") strategy. This confirms the equilibrium $(N C, N C)$, at least, from Wallenstein's perspective. However, Wallenstein wants to take advantage of the Swedes. This necessitates that he pretends choosing "cooperate". But what are Wallenstein's true intentions? "Schiller knows to perfection how to keep these questions open for a long time. Thus Wallenstein remains an enigmatic figure whom neither friend nor foe know what to think of." (Safranski (2007, p.81) Wallenstein to Terzky: “...Might I not mean/ To make you all look foolish? Do you know me?/ I do not think I ever let you see/ The secrets of my heart ..." ("The Piccolomini", Act 2, Scene 5). He seems to waver between two options: either to obtain the Bohemian crown through Swedish support and thereby, obviously disregard the Emperor's objectives, or bring peace to the German lands. Yet, the second alternative would also imply a certain amount of cooperation with the Swedes - which would displease the Emperor as well.

Matrix 2. Wallenstein is striving for the Crown of Bohemia

\begin{tabular}{lccc} 
& & \multicolumn{2}{c}{ Player 2. Swedes } \\
\cline { 2 - 4 } & & $\begin{array}{c}\text { cooperate } \\
C\end{array}$ & $\begin{array}{c}\text { not cooperate } \\
N C\end{array}$ \\
\cline { 2 - 3 } Player 1. & cooperate & $(3,2)^{*}$ & $(-2,1)$ \\
Wallenstein & $C$ & $(2,-2)$ & $(1,0)^{*}$ \\
\cline { 2 - 4 } & $\begin{array}{c}\text { not cooperate } \\
N C\end{array}$ & & \\
\hline
\end{tabular}

Matrix 3. Wallenstein desires peace for the German Reich

\begin{tabular}{lccc} 
& & \multicolumn{2}{c}{ Player 2. Swedes } \\
\cline { 2 - 4 } & & cooperate & not cooperate \\
& & $(2,2)$ & $N C$ \\
\cline { 2 - 3 } Player 1. & cooperate & $(-2,1)$ \\
Wallenstein & $C$ & $(3,-2)$ & $(1,0)^{*}$ \\
\cline { 2 - 3 } & $\begin{array}{c}\text { not cooperate } \\
N C\end{array}$ & & \\
\cline { 2 - 3 } & & &
\end{tabular}


In light of these two options, it is particularly difficult for the Swedes to reach a decision. They try to protect themselves against major disadvantages by taking Eger and Prague as security. Matrices 2 and 3 represent in a most simplified form the two decision situations for the two alternative objectives of Wallenstein. They differ from each other, but also from Matrix 1, because of Wallenstein's payoffs. In game-theoretical language they characterize different types of player 1 .

Matrix 2 shows that Wallenstein prefers the Crown of Bohemia to all other alternatives. This is expressed by the payoff value of 3. To achieve this outcome Wallenstein has to cooperate with the Swedes without any constraints and the Swedes have to fulfil the obligations that come with this cooperation. If the Swedes do not act accordingly, Wallenstein is doomed; this is expressed by -2 , which is his lowest payoff.

But why should the Swedes betray Wallenstein? $(C, C)$ is a Nash equilibrium in pure strategies, and none of the two players can get a higher payoff by choosing unilaterally an alternative strategy. In the given case deviation even hurts the deviator, i.e., the Nash equilibrium $(C, C)$ is strict. However, if a player expects that the other will choose strategy $\mathrm{NC}$, then he will choose his strategy $N C$ as well. The pair $(N C, N C)$ is a Nash equilibrium, however, it is inefficient. There were several signals that indicate that the Swedes did not trust Wallenstein and, in fact, that they could not trust him, so that the equilibrium $(N C, N C)$ was a distinct possibility that Schiller's play keeps alive.

Of course, the Swedes should not trust Wallenstein, if Matrix 3 applies and $N C$ is a strictly dominant strategy for Wallenstein: Whatever the decision of the Swedes, whether they cooperate or not, strategy $N C$ is always Wallenstein's best response. If the Swedes are convinced that Matrix 3 holds, they also choose $N C$. The payoff pair $(1,0)$ then describes the outcome. From the dialogue between Wallenstein and Wrangel one can infer that the Swedes did not know whether Matrix 2 or 3 applies. Thus the decision situation constitutes a game of incomplete information. The Swedes will try to gain information, however, in the end they have to rely on reasonable conjectures. For Wallenstein does not reveal his inmost to anybody, not even to Count Terzky, his brother-in-law and fellow conspirator. A conjecture can be modelled by probabilities $x$ and $1-x$ such that Matrix 2 and Matrix 3 applies, respectively.

In case the Swedes assume that Wallenstein decides to cooperate if he aims for the Crown of Bohemia, they will decide for $C$ if, trivially, the expected utility of choosing $C$ is larger than the expected value of choosing $N C$. The former is $2 x+(-2)(1-x)=$ $4 x-2$ and the latter is $1 x+0(1-x)=x$. The two values are identical for a probability estimate $x=2 / 3$. However, if $x>2 / 3$, then the Swedes are well advised to choose $C$, and if $x<2 / 3$ then they should opt for $N C$.

What do the others think about Wallenstein's objectives? Lieutenant-general Octavio Piccolomini, on the one hand Wallenstein's confidant, on the other hand the Emperor's agent, quite ironically explains to his son Max, colonel of a regiment of cuirassiers, Wallenstein's intention: "He only seeks to bring the Empire peace,/ And as the Emperor detests $t h$ i s peace,/ So he will - fo r c e him to agree to it!/ All parties shall be satisfied, and he,/ As recompense for all his troubles, keep Bohemiawhich he occupies already." Max resists still "That we, that w e should think so basely of him." ("The Piccolomini", Act 5, Scene 1.) 
If we discuss Wallenstein's motifs and goals, it must be kept in mind that we are analysing Schiller's Wallenstein and not the historic person. Schiller, the historian, wrote that "the Duke's treason and his aiming for the Bohemian crown are not based on proven facts but merely on probable assumptions. There is no such document available which would reveal his secret intentions and enables us to determine his presumed course of action beyond historical doubt."7

\section{Magic of chance}

There is a third Nash equilibrium in Matrix 2 that has been neglected so far: the mixed strategy equilibrium $(2 / 3,3 / 4)$. It relates to the Swedes' expectations that Wallenstein is willing to cooperate with a probability $p^{*}=2 / 3$, only. This implication, however, seems rather plausible. The fact that the Swedes asked for Eger and the Old Town of Prague as pledges shows us that their trust in Wallenstein was rather limited. This seems justified and confirmed by a dialogue between Wallenstein and Terzky in "The Piccolomini" (Act 2, Scene 5). "Off, off with them - you do not understand./ Never shall it be said of me I carved/ Up Germany, and sold her to a stranger,/ Just to be sure I had my own share too." Getting pledges promised seems to be a prerequisite for the Swedes to believe in Wallenstein's willingness to cooperate, and $p^{*}=2 / 3$ appears reasonable. At the same time, however, the demand for such collateral means that the Swedish willingness to cooperate is subject to conditions. Wrangel's reservations towards Wallenstein are a strong indicator. An expectation of $q^{*}=3 / 4$ with respect to the Swedish willingness to cooperate seems to be an adequate assumption by Wallenstein.

If Wallenstein and the Swedes choose their strategies $C$ with probabilities $p^{*}=2 / 3$ and $q^{*}=3 / 4$, then neither Wallenstein nor the Swedes can do better by choosing a different strategy. $p^{*}=2 / 3$ is the probability that makes the Swedes indifferent between $C$ and $N C$ and every linear combination of $C$ and $N C$. Thus $p^{*}=2 / 3$ is the solution of equation

$$
2 p+(-2)(1-p)=1 p+0(1-p) .
$$

This result already characterized the equilibrium in Matrix 1, which is not surprising because Matrices 1 and 2 are identical with respect to the payoffs of the Swedes. However, the equilibrium strategies of the Swedes in Matrix 1 and 2 differ.

$$
3 q+(-2)(1-q)=2 q+1(1-q)
$$

If we plug $q^{*}=3 / 4$ into the left or right side of equation (2) we get an expected utility of 1.75 for Wallenstein. If we insert $p^{*}=2 / 3$ into the left or right side of equation (1) then a value of $2 / 3$ results for the Swedes. Obviously this equilibrium is inefficient as both players have larger payoffs if equilibrium $(C, C)$ materializes. However, given $(2 / 3,3 / 4)$, a player cannot do worth by changing his behavior because his payoff is fixed by the mixed strategy of the other player. In the mixed strategy

${ }^{7}$ Quoted after Borchmeyer (2007, p. 14). 
equilibrium player i's payoff is independent of what player i does. This, of course, is a somewhat peculiar result, but matches fully with the equilibrium notion here applied.

A similar reasoning holds true if Wallenstein expects the Swedes to cooperate with a probability of $q^{*}=3 / 4$. Then the expected utility of Wallenstein equals 1.75 , independent of the strategy (and type of behavior) Wallenstein chooses. The mixed strategy equilibrium $\left(p^{*}, q^{*}\right)$ seems to be ruled by some magic. On the one hand, equation (1) shows that $p^{*}$, the mixed strategy of Wallenstein is defined only by the payoffs of the Swedes. In fact, $p^{*}$ makes the Swedes indifferent between their choices $C$ and $N C$. On the other hand, equation (2) is derived from the fact that $q^{*}$ makes Wallenstein indifferent between his strategies $C$ and $N C$. That is why $q^{*}$, the equilibrium strategy of the Swedes, is exclusively defined by the payoffs of Wallenstein. When choosing their equilibrium strategies, the players seem not to consider the payoff they get, but rather the payoff the other player can gain. This holds true in a two-person game when an equilibrium of mixed strategies exists and players can evaluate the payoffs of the other player.

The "magic properties" of the mixed-strategy equilibrium have been widely discussed $^{8}$ and the discussion does not have to be repeated here. However, we want to briefly mention an alternative interpretation of $p^{*}$ and $q^{*}$ that is not based on chance. ${ }^{9}$ Can we read $p^{*}$ and $q^{*}$ as degrees of cooperation? If we assume that $q=1$ represents the case of unconstrained cooperation of the Swedes and $q=0$ the case of their absolute confrontation with Wallenstein, then $q^{*}=3 / 4$, according to this interpretation, expresses a relatively high, but constrained level of cooperation. A player who, like the Swedes, asks for pledges does not want to cooperate without limitations. There will be issues such as the administration of the Old Town of Prague which will not be subject to cooperation. In other areas the players will act even as competitors - for instance, both Wallenstein and the Swedes want to secure the support of Saxony and are courting its prince.

The behavior of the Swedes seems to be adequately described if we interpret the mixed strategies not as probabilities or chance, but as a level of expected action which, after choosing the strategy mix, was actually put into effect. $p^{*}=2 / 3$ is a best response to $q^{*}=3 / 4$, however, it is not the only best response: every $p$ in the interval $[0,1]$ is a best response to $q^{*}=3 / 4$. If $p^{*}=2 / 3$ and $q^{*}=3 / 4$ express levels of cooperation, then $\left(p^{*}, q^{*}\right)$ is a pair of pure strategies as each player chooses his strategy, i.e., the level of cooperation, with probability 1 . The levels, however, are in the interval $(0,1)$.

Is this interpretation convincing with respect to Wallenstein? He has to choose between full cooperation or full confrontation with the Swedes. The mere appearance of cooperating with the Swedes will be interpreted as betrayal by the Emperor and sanctioned accordingly, as we see later from Wallenstein's fate. There seems to be no room for levels of cooperation. Of course, this does not only exclude an interpreta-

\footnotetext{
${ }^{8}$ See Wittman (1985), Tsebelis (1989), Holler (1990, 1993), Frey and Holler (1998) and Andreozzi (2002, 2004). Another peculiarity of the mixed-strategy equilibrium in a 2-by-2 game is the result that the corresponding payoffs are identical to the payoffs that the players achieve in the mixed-strategy maximin solution if the latter exists. However, this is not the case for the games in Matrix 1 and 2. See Holler (1990) and Wittman (1993).

${ }^{9}$ This interpretation derives from still unpublished material by William Heller and Katri Sieberg (2008).
} 
tion of $p^{*}=2 / 3$ as a plausible level but also questions its interpretation as legitimate expectation.

It would appear that the Emperor was present in the room where Wallenstein and Wrangel had their negotiations. This brings us back to the question already mentioned: Who are the players? From the dialogue of Wallenstein and Wrangel we learn that the Swedes are aware of this question and the corresponding problem. Wallenstein is convinced that he has a firm grip on his soldiers and the Emperor therefore has no power over him. But if this were the case then the choice of a $p$-whatever the size of $p$ is - would have an impact only on such goals that Wallenstein wants to achieve with the help of the Swedes. However, Schiller's Wallenstein misjudged the situation he was in.

Often there is a close relationship between the choice of a level and the implementation of a mixed strategy. For instance, this is the case if a certain level of cooperation is put into reality by alternating between full cooperation and confrontation. This is obvious for problems of control if the control is based on sampling. If only every tenth item is examined then this describes the level of control. It is achieved by carefully examining every tenth item and letting the remaining 90 percent pass without examination. The Swedes could have interpreted Wallenstein's staggering behavior as a way to implement a specific degree of cooperation. However, there could be quite a different reason for Wallenstein's staggering, wavering and lack of decisiveness.

\section{The paradox of power and action}

Wallenstein overrated himself and misjudged his generals, colonels and commanders. This certainly contributed to his sharp descent and to his eventual assassination. But he had already been declared an outlaw before he came on stage. "In the beginning, Wallenstein, not knowing anything about the threats, carries on his negotiations and political activities. When confronted with difficulties he slowly gets aware of his being an outlaw - everybody can kill him and the Emperor would pay his murderer a substantial reward. Actually, he was already dead." Such is Peter Stein's resume (2007, p. 38f) of the situation from which Schiller's drama starts. Stein is the director of the theater production which was shown in Berlin. ${ }^{10}$ "One of the play's main topics is the question: what will he do now? He always said: the scope of political behaviour at my disposal is only to open up possibilities, not to take a decision which I put into action. Therefore, the play it is about decision making. He tried to postpone it as long as possible in order to avoid having to actually act accordingly. Sometimes, he handled decisions like a player. Now he is forced - pressured by danger to his life - to make decisions. He is desperately resisting this as he knows that he has power, extensive power, only as long as all possibilities of action are open to him."

Did Wallenstein realize this problem? Was this the reason why he was careful not to document anything in writing ? $^{11}$ Was he, therefore, so affected when Terzky told him

${ }^{10}$ It was performed between May and October 2007 in Berlin-Neukölln, in the former Kindl Brewery.

11 Wallenstein to Count Terzky: ,You know that I put nothing down in writing." ("The Piccolomini”, Act Two, Scene 5.) 
that his secret envoy Sesina had been taken prisoner by soldiers loyal to the Emperor? Stein's (2007, p. 38f.) interpretation is: “... at the very moment of having made one's choice and of implementing same, all other possibilities of choice are destroyed. This means the very decision and the ensuing deed must be taken up full steam; otherwise all other tempting possibilities keep haunting you. In the Greek tragedy, exactly this vehemence of decision is called tragic. There is no good coming from such vehemence, complete power is narrowed by the decision for one option as from now on it becomes a matter of necessity. Suddenly you are determined by what you did or chose to do, you become driven just because you took a decision."

Also field-marshal Illo, confidant of Wallenstein until the end, recognized this very problem. However, for him action was the way out: "For once the step is taken,/ That they will not forgive him in Vienna,/ Then the compulsion of events will lead/ Him on and ever onward. It is choice/ Alone is hard for him; necessity/ Restores his strength, brings clarity again." ("The Piccolomini”, Act 3, Scene 1.) Illo recognizes the powerful consequences of a firm commitment resulting from one's own actions but he is also aware that it "is hard" for Wallenstein to make a choice. Wallenstein does not want to make a choice. He does not want to let go his power and become the agent of his own decisions. He confesses to his brother-in-law Terzky: "It is my pleasure to know the power I have." ("The Piccolomini", Act 2, Scene 5.)

In his article, published in the program of the Stein production in Berlin, Rüdiger Safranski (2007, p. 83) writes, "Of course, for Wallenstein 'power' means nothing else than the strength to have his will rule politically and in society. Power means the ability to act. As Wallenstein says: "If I can no more act, then I am nothing" (Wallenstein's Death, Act 1, Scene 7.) However, his hesitation in deciding implies yet another meaning of power. As a man of power Wallenstein is, like Hamlet, also a man of possibilities. He wants to remain master over his possible actions. Reality is but a constriction, it reduces the possibilities. Reality is what remains when the multitude of possibilities are squeezed through the eye of the needle of decision. The reality which you have opted for is captivating and entangles you in the independent logic of facts, although it is you who created them. This is why Wallenstein hesitates. He wants to keep his options. As man of power he wants to act, and yet he shuns the irreversibility of action. He wants to be both, a man of power and a man of possibilities."

These two options are contained in Max Weber's classic definition of power "as the probability that one actor within a social relationship will be in a position to carry out his own will despite resistance, independent of the basis of such probability." (Weber translated by Talcott Parsons, 1947, p.152.) This probability does not mean likelihood but it is a potential defined by the resistance of the others. It describes possibilities to act but not acting as such. One's own action can enlarge or reduce this potential, which is also true for the action of others. Wallenstein was afraid that his power would be reduced by his action. However, he underestimated the scope by which his potential to act was diminished and even destroyed by the action of others.

There is a voluminous game-theoretical literature on power. However, this work should not be discussed here. We limit ourselves to illustrate the problem of power by game forms. Nicholas Miller (1999) calls the game form a "game without preferences." 
The cells of Matrix 4 do not contain payoffs, but outcomes (or events). The application of game form modelling thus illustrates that the notion of power does not refer to preferences. Power does not depend on what agents want but what they can achieve. The measure for power is what an agent can achieve "despite resistance" (see Weber's definition above).

Matrix 4. Game form of power

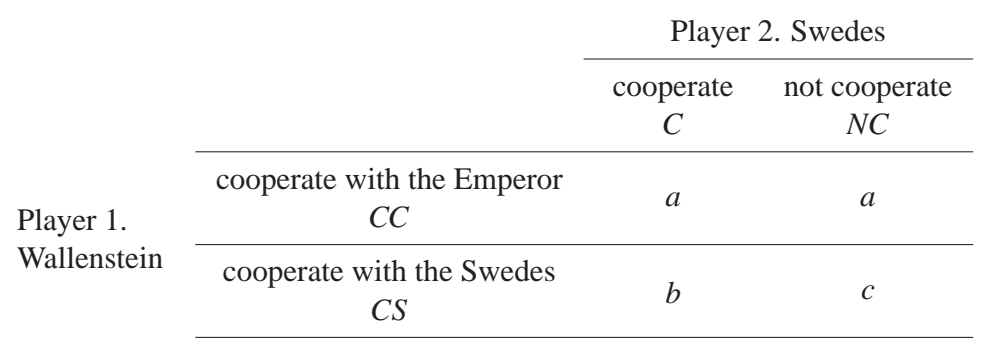

Matrix 4 says that if Wallenstein decides to cooperate with the Emperor then there will be an outcome $a$, irrespective of whether the Swedes offer cooperation to Wallenstein or not. Strategy $C S$, cooperation with the Swedes can be interpreted as in Matrices 1-3. However, it is not obvious what cooperation with the Emperor, i.e., strategy $C C$, implies and, correspondingly, what the outcome $a$ could be? We have to guess because in Schiller's play there is nothing conclusive for this case. Perhaps it means that Wallenstein will resign from the command of his troops and retire to his small dukedom just as his sister-in-law, Countess Terzky, more or less ironically proposed in Act 1, Scene 5, of "Wallenstein's Death." The outcome $b$ could be the Crown of Bohemia and peace for the German Empire, given the assumption that Wallenstein's troops are loyal to him. Outcome $c$ is likely to be Wallenstein's downfall as the Emperor and the Swedes turn out to be his enemies.

If we compare the power of the Swedes to the power of Wallenstein in accordance with the decision situation in Matrix 4, we may conclude that Wallenstein has more power than the Swedes: Wallenstein controls the set of outcomes $\{a\}$ and thus can put outcome $a$ into reality even against the resistance of the Swedes. The Swedes control two sets of outcomes: $\{a, b\}$ and $\{a, c\}$. Thus they can neither realize $a$ nor $b$ nor $c$ against Wallenstein's resistance. In this case, we say that Wallenstein is effective for $\{a\}$. In fact, whether the decision of player 2 is relevant depends on the decision of player 1 , while player 1 does not depend on player 2 if he chooses strategy $C C$. Also, since $\{a\}$ is a strict subset of $\{a, c\}$ it seems plausible to conclude that player 1 is more powerful than player 2 .

When negotiating with Wrangel, Wallenstein would have liked to exploit the power situation outlined in Matrix 4. However, Wrangel convinces him that Wallenstein can no longer hope for cooperating with the Emperor after his secret envoy Sesina was caught by troops loyal to the Emperor. If we erase strategy $C C$, the resulting game form reflects that Wallenstein has no power in the interaction with the Swedes, i.e., he is impotent. However, the degree of his impotency is neither obvious to the Swedes 
nor to Wallenstein when he is negotiating with Wrangel. Wallenstein still believes that his troops are absolutely loyal to him and he even succeeds in convincing the Swedes.

\section{Wallenstein's death}

After Wallenstein decides, despite the unfavourable point of departure, to form an alliance with the Swedes, nothing remains now that can prevent his downfall. His confidants as well as his regiments are turning their back upon him one after another. While totally overrating his own influence and misjudging the facts, he commits a number of serious mistakes. For instance, despite being warned by his closest intimates, his brother-in-law Terzky and his field-marshall Illo, he continues to consider Octavio Piccolomini one of his most loyal friends. He trusts him with a task of utmost strategic importance - to keep away the Spanish troops who are allies to the Emperor. When Wallenstein learns that the Emperor declared Octavio Piccolomini his successor, his regiments desert him and join the new imperial commander, it is too late for counter measures. The situation deteriorates ever more: Butler, a commander of a regiment of dragoons, reports that Prague is lost for him and the Swedes, his regiments have sworn the oath of allegiance to the Emperor anew, and he, Terzky, and Illo are declared outlaws ("Wallenstein's Death", Act 3, Scene 10).

But Wallenstein also misinterprets the tough old soldier Butler, believing until the end that he is faithful to him. However, after hearing from Octavio Piccolomini that Wallenstein had shamefully betrayed him, Butler deserted to the imperial troops. Despite his humble background, he had worked his way up to the position of commander of a regiment of dragoons. At one point, Wallenstein urged him to submit to the Emperor a request for the title of count. But the request was refused as Wallenstein had spoken most scornfully of Butler in a letter to the minister in charge. Piccolomini shows Butler this very letter, adding that Wallenstein wanted "... to make you his blind instrument, to use/ You as the means to his perfidious purpose." ("Wallenstein's Death", Act 2, Scene 6.) Only once (in Act 3, Scene 4) Wallenstein shows signs of guilt towards Butler, and a sense of foreboding enters his mind. But he does not see that Butler is now playing false with him, in order to enact his revenge.

Wallenstein believes that Max Piccolomini, the commander of the Pappenheim regiment, will remain loyal to his cause. But the young Piccolomini implores him not to become a traitor as "...that is quite another thing - is black/ As black as hell itself!" He even begs him to send him to Vienna "... and let me / Me, reconcile you to the Emperor." ("Wallenstein's Death", Act 2, Scene 2.) Max Piccolomini seems to understand that only such a move can restore Wallenstein's freedom to act - and save his life.

Shortly after this dialogue, Wallenstein is told by Countess Terzky that Max Piccolomini and his daughter Thekla have fallen in love with each other and that Max intends to ask him for Thekla's hand. Misjudging the situation completely he replies that he has other plans for the future of his daughter: "And I am now, like any fond/ Soft-hearted father of a lowly rank,/ To give my blessing to their match of love?" $\mathrm{He}$ wants to give his daughter in marriage for a king's royal sceptre only ("Wallenstein's Death, Act 3, Scene 4). 
Towards the envoys of Pappenheim's regiment who want to hear from him personally that he is not a traitor as stated in a letter from the Emperor which had come in their hands, he acts like a superior general who cares for his soldiers like for his own children. "... This war will swallow up us all./ Austria wants no peace, and for that reason,/Because I work for peace, so I must fall.” A few lines later he explains to them: "If Sweden offers help, then let us seem/ To take it, till,...we... lead forth, before the world/ Rejoicing, peace with fairest garlands crowned." ("Wallenstein's Death", Act 3, Scene 15.) His manoeuvering reaches its peak when he openly declares: "What do I care for Sweden? I detest her,/ Worse than the pit of hell, and with God's help/ I hope to drive her back across the Baltic." ("Wallenstein's Death", Act 3, Scene 15.)

When he is about to convince the Pappenheimers of his arguments, Butler enters, all excited, breaking the news that "Terzky's regiments are tearing down/ The eagle of the Empire from their standards,/ And setting up your badge instead!" ("Wallenstein's Death", Act 3, Scene 16.) Butler is certainly aware that this piece of information is destroying Wallenstein's credibility - and so it happens. The Pappenheimers opt for the Emperor and against Wallenstein.

For the last time, Max Piccolomini visits Wallenstein's quarters in Pilsen to bid farewell to Thekla: "I must, I must desert you, Thekla... And yet I cannot take with me your hatred./ Only a single glance of pity grant me,/ Say that you do not hate me." Full of grief he asks, "Why must the guilt/ And wickedness our fathers share...। Why the unyielding hatred of our fathers/ Sunder us too, and rend our bond of love?" ("Wallenstein's Death", Act 3, Scene 18.) When Wallenstein and Countess Terzky urge him to make up for his father's betrayal by remaining faithful to Wallenstein, Max becomes uncertain. He turns to Thekla: "Speak, can you love me still, if I stay here?/ Say that you can, and I will be your man." ("Wallenstein's Death", Act 3, Scene 21.) Upon Thekla's reply he decides in favour of the duty which means to remain loyal to the Emperor. These are Thekla's last words to him: "True to yourself, you will be true to me./ Fate parts us, but our hearts remain united." In an act of despair, Max and his regiment of Pappenheimers throw themselves into a battle against the Swedes. All of them are killed.

Act 4 and 5 take place in Eger where Wallenstein intends to unite with the Swedes the next day. At the fortress of Eger he feels safe surrounded by the few confidants who have stayed with him: Terzky, Illo and - as he believes - Butler. Yet, he has a premonition and a certain longing for death. When he is told that the young Piccolomini was killed, he states: "His the good fortune. He has made an end./ There is no future more for him, now fate/ Spins no more treachery. ..." But when his sister-in-law, Countess Terzky, tells him her horrible dream, he tries to calm her down: "The Emperor's proscription frets you./ Words/ Can do no hurt, and hands will not be found." ("Wallenstein's Death", Act 5, Scene 3.) However, he is clearly aware of the dire constellation of the stars. His astrologer Seni warns him: "You must not wait until the Swedes are here!/ False friends are close at hand, and danger threatens, / The signs are terrifying, close, close by/ You are surrounded by disaster's net." ("Wallenstein's Death", Act 5, Scene 5.)

When the commander of the fortress, Gordon, a childhood friend, implores him to 
make amends for ill and not to ally with the Swedes he takes refuge in his philosophy of power and no action: "If I had known before what now has happened,/ That it would rob me of my dearest friend -/ Perhaps, I had done otherwise-perhaps/ Had not-But what should we spare now? Too deadly earnest/ It has begun, for it to come to nothing./ So let it run its course!" ("Wallenstein's Death" Act 5, Scene 5). At the end, his last words are: "I hope that I shall have a long night's sleep,/ For great has been the toil of these last days./ See it is not too early that they wake me!"

What Seni predicted by watching the stars then occurs. By order of his "false" friend Butler, Wallenstein is murdered in his bedroom. Butler also gives order to kill the other two outlaws, Count Terzky and Field-Marshal Illo, during the banquet held at the castle. Countess Terzky takes poison. Wallenstein's wife, the Duchess, is dying and her daughter Thekla is missing. She went clandestinely to the convent of Saint Catherine to die beside Max Piccolomini's tomb who was buried there in due honor. At last, not the Swedes but the imperial army led by Octavio Piccolomini take over Eger.

\section{The game is over}

In the very last scene, Octavio Piccolomini receives a letter from the Emperor. It is addressed to Prince Octavio Piccolomini. Schiller writes in his stage directions "Octavio starts in horror and looks sorrowfully up to heaven." Is he contemplating the high price he had to pay for the title of a Prince? It does not matter as it is just a game. But game and earnestness are closely associated in Schiller's Wallenstein. Terzky asks Wallenstein "What can it mean to you,/ When you have won the fame/12 who pays for it?" ("The Piccolomini", Act 2, Scene 5.) Countess Terzky asks Thekla who is in love "Do you think/ That you have won your game already?/ Do not rejoice too soon!" ("The Piccolomini", Act 3, Scene 8.) Butler sees through the game that Illo and Terzky are "playing with the pledge of the officers" to Wallenstein. ${ }^{13}$

The games played in this dramatic poem demand a game-theoretical analysis. Also, Schiller's Wallenstein is suitable for an exemplary game-theoretical examination as the main character seldom acts and yet, takes decisions regarding life and death, even war and peace, which he explicitly reflects upon. Furthermore, the people around him comment on his decisions from different angles. In this drama there is altogether not much action but more dialogue which is almost paradoxical in view of the bloody scenes in "Wallenstein's Death". This simplifies the game-theoretical analysis as it can concentrate on the few, therefore all the more crucial, decisions. Of course, the love between Thekla and Max falls a bit short, but it has no "strategic" component: It is

\footnotetext{
12 As the translator of this paper notes, the literal translation of the German line: "Wenn du das S p i e 1 gewinnst..." would be: ,When you have won the g a m e ...". However, Lamport, in his Wallenstein translation preferred the word "fame" - or is it a typo?

13 "Let not my words dismay you, gentlemen,/ You will not be concerned ho w you have won me,/ And scarcely will yourselves expect, I think,/ That tricks of crookedness will mar my judgement - / Scarcely believe hot blood or fickle temper/ Or such slight cause could tempt a grey-haired man/ To quit the path of honour, trod so long." ("The Piccolomini", Act 4, Scene 4.) Here Schiller is playing with the audience as in the end it is Butler who gives the order to kill Wallenstein, Illo, and Terzky.
} 
direct; it is not the result of strategic decisions, but dominated by emotions.

The scene where Terzky and Illo trick their fellow officers into signing the oath, demonstrates convincingly that Wallenstein's surrounding is manipulative and unstable. He believes in his soldiers' loyalty but apparently his closest confidants do not otherwise they would not resort to fraudulent means to obtain signatures of loyalty.

A second dimension has not been mentioned here so far: the relationship between soldiers and civilians and the soldiers' fear of peace. However, under game-theoretical aspects, these facts may be ignored. It does not make much sense as the actors remain for the most part anonymous. On the other hand, there are numerous scenes in "Wallenstein's Camp" that imply strategic interaction. But Schiller included these scenes in order to illustrate the setting and the historical background of the important decisions which we were dealing with in this paper.

What can we say about Wallenstein's inclination towards astrology? Game theory, based on rationality, seems to present a certain contradiction to this discipline. But there are enough signs that at the time of Wallenstein, astrology was considered a science. Due to Tycho Brahe's observations of planetary orbits and because the Copernican conception of the world became widely known and acknowledged, astronomy advanced profoundly. "In many universities, astrology was taught in tandem with astronomy as one of the seven classical liberal arts (the others being grammar, dialectic, rhetoric, geometry, arithmetic, and music)" (Gilder and Gilder, 2004, p.11). If you can forecast the eclipse of the sun or moon, you should also be able to predict the fate of a person like Wallenstein. The famous astronomer Johannes Kepler casted Wallenstein's horoscope. It could be considered "rational" that Wallenstein kept to the stars and to his astrologer Seni. Yet, his remark "False friends have been the whole of my misfortune./ Your words of warning should have reached me sooner, I do not need the stars to tell me now." ("Wallenstein's Death", Act 5, Scene 5) shows a rivalling consciousness with a strong inclination for reality. What good does it do to be warned by the horoscope when misery is already on its way and cannot be stopped? In such a situation stars are no longer necessary to watch.

Interpreting the negotiations between Wallenstein and Wrangel from a game-theoretical point of view shows that they can be considered rational if looked upon in isolation. However, such a limited perspective proves to be deceptive. Wallenstein did not consider his officers to be active players. Thus he violated a basic principle of game theory, i.e., to ask the question: "Who are the players?" This also holds with respect to the Emperor whom he included in his strategies but he did not think of him as a player. This was "decisive for the game". Matrix 4 illustrates Wallenstein's main problem: He wants his power defined by the possibilities to act, not to be reduced by decisions and actions. If he had evaluated his officers and the Emperor's role and objectives more realistically, he would have judged the potential of his actions and thus his power to be much smaller. Power can be an illusion. In the end, Wallenstein was victim to his power illusion.

Once more we want to point out that we are dealing with Schiller's Wallenstein. There is no evidence that the historic Wallenstein negotiated with the Swedes and that he committed high treason. Schiller remarks about the historic figure: "It is a misfor- 
tune for him alive that he made a winning party his foe - a misfortune for him dead that this foe survived him and wrote his history. ${ }^{14}$

Acknowledgment We greatly benefited from helpful comments by Siegfried BouvierErtlé, Mark Kenny, Vikas Kumar, Heidi Linsmayer, Jens Tiedemann, and two anonymous referees. Any remaining errors are our own.

\section{References}

Andreozzi, L. (2002). Oscillations in the Enforcement of Law: An Evolutionary Analysis. Homo Oeconomicus, 18, 403-428.

Andreozzi, L. (2004). Rewarding Policeman Increases Crime: Another Surprising Result from the Inspection Game. Public Choice, 121, 62-82.

Baxandall, M. (1985). Patterns of Intention: On Historical Explanation of Pictures. New Haven and London, Yale University Press.

Frey, B. S. and Holler, M. J. (1998). Tax Compliance Policy Reconsidered. Homo Oeconomicus, 15, 27-44.

Borchmeyer, D. (2007). Macht und Melancholie. Programmbücher des Berliner Ensemble, 89, 10-15.

Gilder, J. and Gilder, A. (2004). Heavenly Intrigue: Johannes Kepler, Tycho Brahe, and the Murder behind one of History's Greatest Scientific Discoveries. Armonk, New York, Baror International, Inc.

Godel, R. (1999). Schillers Wallenstein-Trilogie. Eine produktionstheoretische Analyse. St. Ingbert, Röhrig Universitätsverlag.

Heller, W. B. and Sieberg, K. K. (2008). Functional unpleasantness: The evolutionary logic of righteous resentments. Public Choice (forthcoming).

Holler, M. J. (1990). The Unprofitability of Mixed Strategy Equilibria in Two-Person Games: A Second Folk-Theorem. Economics Letters, 32, 319-32.

Holler, M. J. (1993). Fighting Pollution When Decisions are Strategic. Public Choice, 76, 347-356.

Miller, N. (1999). Power in Game Form. Homo Oeconomicus, 16, 219-243. An earlier version of this paper has been published in Holler, M. J. (ed.), (1982), Power, Voting, and Voting Power. Würzburg und Wien, Physica-Verlag, 33-51.

Oellers, N. (2005). Wallenstein. In Luserke-Jaqui, M. (ed.), Schiller-Handbuch. LebenWerk-Wirkung. Stuttgart, Verlag J. B. Metzler, 113-153.

Safranski, R. (2007). Friedrich Schiller oder die Erfindung des deutschen Idealismus. Programmbücher des Berliner Ensemble, 89, 80-84.

14 Quoted after Borchmeyer (2007, p.14). 
Schiller, F. (1798 onwards). Wallenstein. Translated with an Introduction by F. J. Lamport (1979), The Robbers and Wallenstein. London, Penguin Books.

Stein, P. (2007). Wieso überhaupt Wallenstein? Aus einem Gespräch mit Peter Stein. Programmbücher des Berliner Ensemble, 89, 36-41.

Tsebelis, G. (1989). The Abuse of Probability in Political Analysis: The Robinson Crusoe Fallacy. American Political Science Review, 83, 77-91.

von Neumann, J. (1928). Zur Theorie der Gesellschaftsspiele. Mathematische Annalen, 100, 295-320.

von Neumann, J. and Morgenstern, O. (1944). Theory of Games and Economic Behavior. Princeton, Princeton University Press.

Weber, M. (1947). The Theory of Social and Economic Organization edited by T. Parsons. New York, Free Press.

Wittman, D. (1985). Counter-intuitive Results in Game Theory. European Journal of Political Economy, 1, 77-89.

Wittman, D. (1993). Nash Equilibrium vs. Maximin: a Comparative Statics Analysis. European Journal of Political Economy, 9, 559-565. 